\title{
Bladder Macrolithiasis Complicating Vesical Neck Stenosis, A Rare Cause of Renal Failure: A Case Report
}

\author{
R.Allali $^{1 *}$, R.Ait Ouali ${ }^{1}$, M. Aarab ${ }^{1}$, A.Mortaji ${ }^{1}$, M.A. Lakmichi ${ }^{1}$, Z. Dahami ${ }^{1}$, M.S. Moudouni ${ }^{1}$, I. Sarf ${ }^{1}$
}

${ }^{1}$ Service d’Urologie, Hopital Errazi, Centre Hospitalier Universitaire Mohammed VI de Marrakech, Morocco

DOI: $\underline{10.36347 / \text { simcr.2022.v10i01.013 }}$

| Received: 30.11.2021 | Accepted: 04.01.2022 | Published: 30.01.2022

*Corresponding author: Rachid Allali

Service d'Urologie, Hopital Errazi, Centre Hospitalier Universitaire Mohammed VI de Marrakech, Morocco

Abstract

Bladder lithiasis refers to the disease associated with the formation of stones in the bladder. These stones, which can reach several centimetres in size, are formed from aggregates of various mineral and organic substances. Most often these stones are formed as a result of poor bladder evacuation. We report a case of bladder macrolithiasis associated with two stones: right ureteral and renal on bladder neck stenosis revealed by hypogastric pain and signs of lower urinary tract and complicated by renal failure in a 42 year old patient. The physical examination revealed bilateral lumbar tenderness and a hard hypogastric palpable mass. Imaging revealed the presence of a bladder macrolithiasis occluding almost the entire bladder associated with a pelvic ureter stone and a right renal corraliform stone. The treatment consisted of a suprapubic cystotomy with extraction of the macro bladder stone and the ureteral stone delivered through the meatus by ureterolithotomy with cervical incision of the bladder neck. The postoperative course was simple. The evolution was marked by the normalization of the renal function. The patient underwent a lumbotomy for his right kidney stone 2 months later.

Keywords: Macro-lithiasis, Cystotomy, Ureterolithotomy, Renal failure, Stenosis.

Copyright $\odot 2022$ The Author(s): This is an open-access article distributed under the terms of the Creative Commons Attribution 4.0 International License (CC BY-NC 4.0) which permits unrestricted use, distribution, and reproduction in any medium for non-commercial use provided the original author and source are credited.

\section{INTRODUCTION}

Lower urinary tract calculi, formerly known as stone disease, is common in patients of low socioeconomic status, hence its name lithiasis of the poor or endemic lithiasis [1].

Bladder stones are most often secondary to a subvesical obstruction or an intravesical foreign body, and are generally discovered in the presence of irritative and ostructive urinary signs: haematuria, micturitional burning, pollakiuria, micturitional urgency, dysuria.

On the other hand, in well-targeted populations, lithiasis of the lower urinary tract is very frequent. This is mainly the case in neurological patients with severe motor impairment: tetraplegia, advanced MS etc [2].

We report a case of bladder macrolithiasis discovered in a 42-year-old patient.

\section{ObServation}

We report the case of a42 years old patient, without any particular pathological history, admitted via the emergency room for chronic hypogastric pain evolving for 20 years, accentuated 6 months ago, associated with right lumbago with symptoms of lower urinary tract type emptying and filling: pollakuria, dysuria.

The clinical examination revealed bilateral lumbar tenderness, with the presence of a hard hypogastric mass. AUSP revealed several calciumtoned opacities projecting into the right renal area and the superior strait (Figure 1).

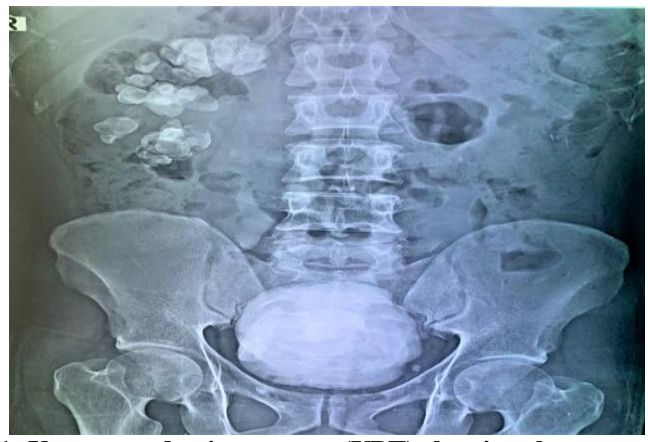

Fig-1: Unprepared urinary tract (UPT) showing the presence of several calcium-toned opacities in the bladder area, pelvic area, and right renal area. 
An initial biological work-up was ordered and revealed acute renal failure, with hyperkalemia and metabolic acidosis. Creatinine was $53.2 \mathrm{mg} / \mathrm{L}$ with a glomerular filtration rate (GFR) of $15 \mathrm{ml} / \mathrm{min}$, urea was $1.5 \mathrm{~g} / \mathrm{L}$, kalemia was $5.9 \mathrm{mml} / \mathrm{L}$, and bicarbonates were $15 \mathrm{mml} /$ L.Phosphocalcic balance was normal. CRP was 13.56. Uric acid was $69 \mathrm{mg} / \mathrm{L}$. The cytobacteriological examination of the urine (ECBU) was positive, isolating a Proteus Mirabilis sensitive to 3rd generation cephalosporins. The haemogram and liver function tests were unremarkable.

The uroscanner showed a major bilateral ureterohydronephrosis upstream of a bladder macrocalculus measuring 89x80mm (850UH), associated with a right distal ureteral calculus measuring $2 \mathrm{~cm}(1100 \mathrm{UH})$ and a right corraliform with bilateral cortical thinning (Figures 2, 3, 4, 5).

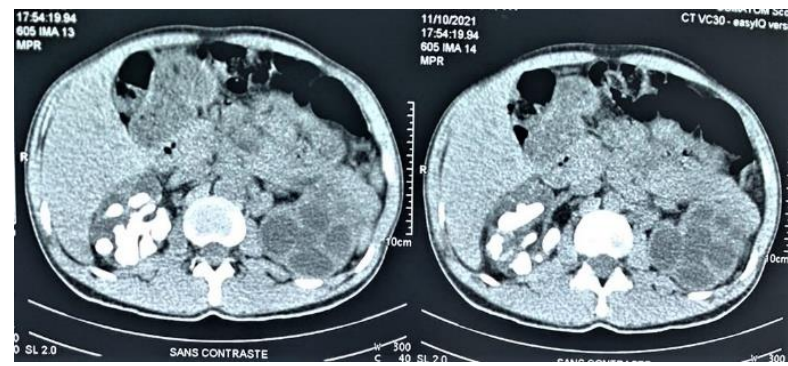

Fig-2: CT-scan showing bilateral renal dilatation with large right corral stone and bilateral cortical thinning

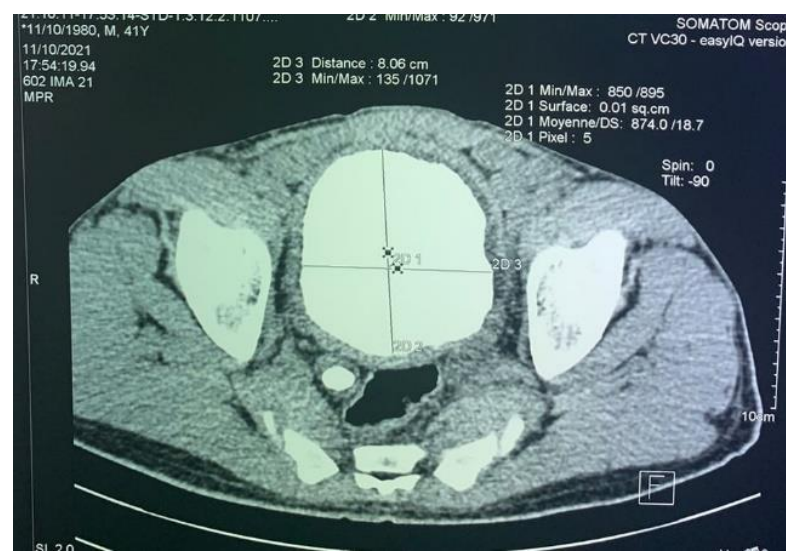

Fig-3: Transversal scan section showing a macro-calculus occupying almost the entire bladder with pelvic ureteral calculus

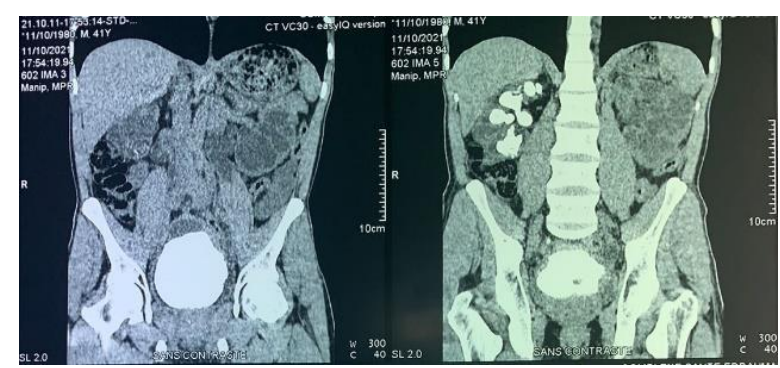

Fig-4: Frontal scan section showing bilateral renal dilatation upstream of a bladder macrolithiasis occupying almost the entire bladder with a right corraliform
After treatment of the urinary tract infection and correction of the hyperkalemia, the patient underwent cystotomy with extraction of a $10 \mathrm{~cm}$ yellowish macro bladder stone with a rough surface (Figure 6), and a ureteral stone delivered through the right meatus by ureterolithotomy (Figure 7). Intraoperatively, a stenosis of the cervix was found and was treated by cervicoprostatic incision. The postoperative course was simple. Both stones were sent for structural and spectrophotometric study. The evolution was marked by an improvement of the renal function. The patient benefited 2 months later from a cure of his right kidney stone by surgical lumbotomy.

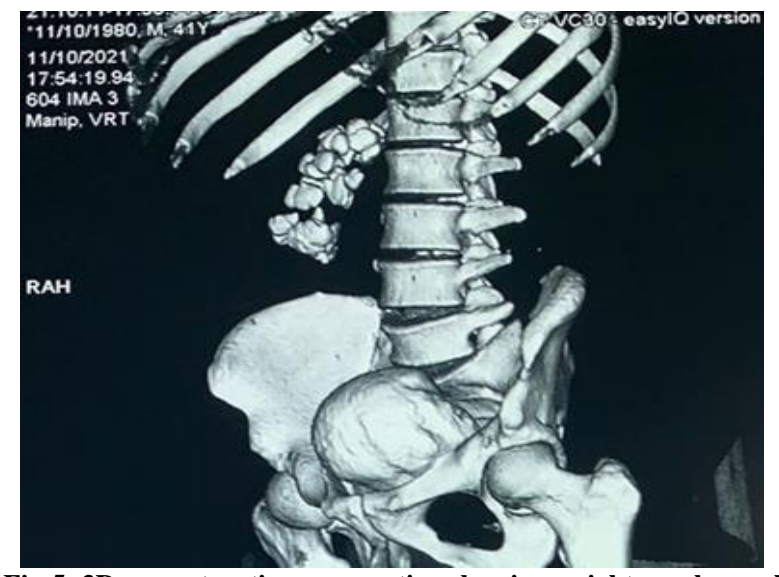

Fig-5: 3D reconstruction scan section showing a right renal corral stone and a bladder macro stone

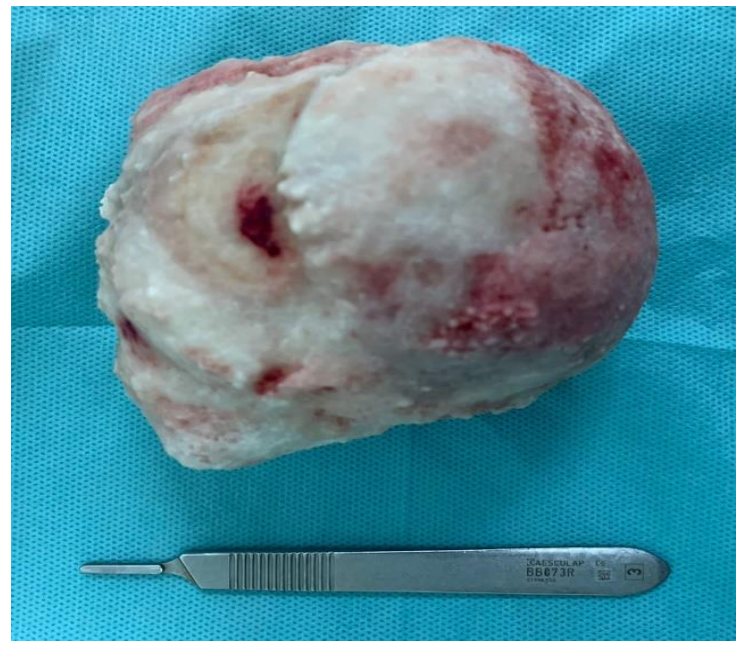

Fig-6: Extraction of a $10 \mathrm{~cm}$ bladder macrolithiasis

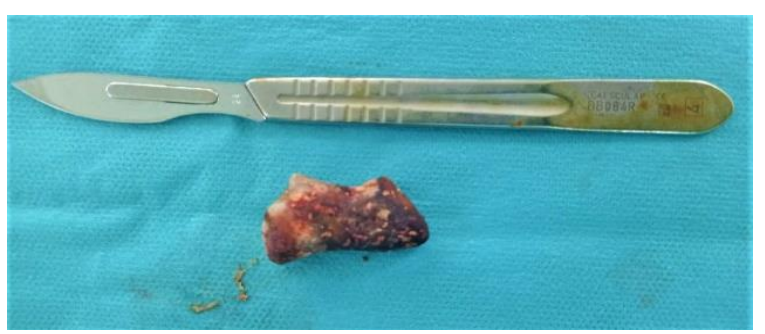

Fig-7: Extraction of a $3 \mathrm{~cm}$ stone from the pelvic ureter delivered through the ureteral meatus. 


\section{DiSCUSSION}

Although it is a common disease, lower urinary tract calculosis is more common in underdeveloped countries[1].

In the West, lower urinary tract lithiasis, which was common until the 19th century, has almost disappeared with the improvement of living conditions.

In Africa, urinary tract infections remain a public health problem due to the low standard of living of the population and the existence in most countries of a hot, dry climate with high temperatures responsible for dehydration[3]. Lithiasis of the lower urinary tract occurs in most cases in the context of obstruction of the lower urinary tract, both in children (posterior urethral valves with delayed diagnosis) and in adults (prostatic pathology, urethral stenosis or bladder neck disease, or in a context of neurological bladder) [4].

Physical examination is only useful for large stones that are palpable above the pubic bone or on pelvic touch [5], as in our patient's case. Imaging; AUSP, ultrasound and above all uroscanner; allows a positive diagnosis, an assessment of the impact on the upper urinary tract and the identification of the aetiology.

Stones are often secondary [6]. This is the case in our patient where a tight bladder neck stenosis was discovered. Those without obvious causes, known as idiopathic primary stones [7], are rare. Chronic urinary tract infections are evoked in front of phosphoamoniaco-magnesic stones [8]. Neurogenic bladders are the cause of destasis stones.

Large stones occupying the entire bladder lumen exert mechanical compression on the ureteral meatus, leading to obstruction and renal failure[9], which was the case for our patient.

The initial treatment is for infectious and obstructive complications of the stone. The extraction technique depends on several factors, including size, composition, comorbidities, surgical history, and the presence or absence of anatomical malformations of the lower urinary tract. Endoscopic extraction after fragmentation is indicated for stones smaller than $2 \mathrm{~cm}$, for those between 2 and $4 \mathrm{~cm}$ percutaneous cystolithotomy is recommended, while for stones larger than $4 \mathrm{~cm}$ open surgical extraction remains the most recommended technique[1]. Extracorporeal lithotripsy is indicated for stones smaller than $2 \mathrm{~cm}$ in patients at high surgical risk with a success rate of $72 \%$ to $100 \%[2]$.
Extraction of the stone in our case was done by cystotomy, a technique described in the majority of cases in the literature for large stones [9]. Prevention consists of treatment of the causative etiology combined with hygienic and dietary measures adapted to the type of stone [9].

\section{CONCLUSION}

Lithiasis of the lower urinary tract is very common in elderly subjects with underlying urological abnormalities.Management consists not only of simple stone removal, but also treatment of the etiology involved. A giant stone requires an assessment of its impact, especially on the upper apparatus. The formation of a bladder stone is chronic, the patient may remain asymptomatic for a long time, hence the importance of an early diagnosis. Renal failure secondary to a giant stone is rare, such is the particularity of our case.

\section{REFERENCE}

1. Bah, I. (2009). La lithiase du bas appareil urinaire: Analyse rétrospective de 111 cas au CHU de Conakry. African Journal of Urology, 15(1).

2. Chapitre 15 - Lithiase urinaire [Internet]. 2016.:https://www.urofrance.or/congresetformations/formationinitiale/referentiel-ducollege/lithiase-urinaire.html

3. Bouchet, H. (1999). Chirurgie de la lithiase vésicale au XIXe siècle. In Annales de chirurgie (Paris) (Vol. 53, No. 9, pp. 908-914).

4. Mahamat, M. A., Ngaringuem, O., Abakar, A. M. N., Jalloh, M., Hamat, I., Niang, L., \& Gueye, S. M. (2017). La lithiase du bas appareil urinaire: Aspects diagnostiques et thérapeutiques à l'Hôpital de la Mère et de l'Enfant (HME) à N'Djamena (Tchad). African Journal of Urology, 23(4), 295299.

5. Hanumanthaiah, K. S., \& Yasaswini, H. (2014). Giant vesical calculus--a case report. Journal of Evolution of Medical and Dental Sciences, 3(22), 6270-6273.

6. Bayindir, M., Reșorlu, B., Sarikaya, S., Șahin, E., \& Ünsal, A. (2012). A Giant Bladder Stone In A Middle-Aged Female Patient Without Any Predisposing Factor: case report.

7. Chawla, A., Mishra, D. K., \& Kumar, S. P. (2014). Secondary vesical calculus in female. Austin $J$ Urol, 1(3), 2.

8. Onuk, Ö., Can Balcı, M. B., Hazar, A. İ., Taş, T., Özkan, A., \& Nuhoğlu, B. (2014). Giant Bladder Stone in a Young Woman. Journal of Academic Research in Medicine, 4(3).

9. Ofluoglu, Y., Aydin, H. R., Kocaaslan, R., Adanur, S., \& Ziypak, T. (2013). A cause of renal dysfunction: a giant bladder stone. The Eurasian journal of medicine, 45(3), 211. 